\title{
Glyceollin is an Important Component of Soybean Plant Defense Against Phytophthora sojae and Macrophomina phaseolina
}

\author{
Anatoliy V. Lygin, Olga V. Zernova, Curtis B. Hill, Nadegda A. Kholina, \\ Jack M. Widholm, Glen L. Hartman, and Vera V. Lozovaya
}

First, second, third, fourth, fifth, and seventh authors: Department of Crop Sciences, University of Illinois, 1201 W. Gregory Drive, Urbana 61801; and sixth author: United States Department of Agriculture-Agricultural Research Service, University of Illinois, 1101 W. Peabody Drive, Urbana 61801.

Accepted for publication 16 April 2013.

\begin{abstract}
Lygin, A. V., Zernova, O. V., Hill, C. B., Kholina, N. A., Widholm, J. M., Hartman, G. L., and Lozovaya, V. V. 2013. Glyceollin is an important component of soybean plant defense against Phytophthora sojae and Macrophomina phaseolina. Phytopathology 103:984-994.

The response of soybean transgenic plants, with suppressed synthesis of isoflavones, and nontransgenic plants to two common soybean pathogens, Macrophomina phaseolina and Phytophthora sojae, was studied. Transgenic soybean plants of one line used in this study were previously generated via bombardment of embryogenic cultures with the phenylalanine ammonia lyase, chalcone synthase, and isoflavone synthase (IFS2) genes in sense orientation driven by the cotyledon-preferable lectin promoter (to turn genes on in cotyledons), while plants of another line were newly produced using the IFS2 gene in sense orientation driven by the Cassava vein mosaic virus constitutive promoter (to turn genes on in all

moter compared with the untransformed control during the 10-day observation period, with the precursors of isoflavone synthesis being accumulated in the cotyledons of transgenic plants. These results indicated that the lectin promoter could be active not only during seed development but also during seed germination. Downregulation of isoflavone synthesis only in the seed or in the whole soybean plant caused a strong inhibition of the pathogen-inducible glyceollin in cotyledons after inoculation with $P$. sojae, which resulted in increased susceptibility of the cotyledons of both transgenic lines to this pathogen compared with inoculated cotyledons of untransformed plants. When stems were inoculated with M. phaseolina, suppression of glyceollin synthesis was found only in stems of transgenic plants expressing the transgene driven by a constitutive promoter, which developed more severe infection. These results provide further evidence that rapid glyceollin accumulation during infection contributes to the innate soybean defense response.
\end{abstract} plant parts). Nearly complete inhibition of isoflavone synthesis was found in the cotyledons of young seedlings of transgenic plants transformed with the IFS2 transgene driven by the cotyledon-preferable lectin pro-
Additional keywords: disease resistance, Glycine max, lignin.
Biotic stress is a primary cause of soybean crop loss worldwide, and yield reduction caused by plant pathogens alone has been estimated at $11 \%$ per year (21). For plants to withstand and survive stresses produced by abiotic and biotic constraints, different resistance mechanisms have evolved. The ability to recognize invading microbes and then respond biochemically to prevent or limit the invasion in plant cells is a well-established plant process that has been studied extensively $(4,10-12,16,35)$. When an incompatible reaction occurs between the host and pathogen, a resistance response is induced involving multiple parts of the innate immune system, which increases the activity of local and systemic biochemical pathways that produce compounds that can directly restrict pathogen colonization. One essential part of the innate immune system is the production of secondary metabolites, which are toxic to many pathogens and are either preformed or induced after host recognition of pathogen elicitor molecules $(5,36,37,44,45)$. There is a large body of experimental results indicating the important roles of antimicrobial secondary metabolites in plant defense when they are rapidly produced in effective concentrations after pathogen attack and in appropriate plant tissues $(2,20,48)$.

Phenylpropanoids are known to be involved in plant-pathogen interactions and can be strongly toxic or inhibitory to pathogens

Corresponding author: V. V. Lozovaya; E-mail address: lozovaya@uiuc.edu

http://dx.doi.org/10.1094/PHYTO-12-12-0328-R

(C) 2013 The American Phytopathological Society when either constitutively formed (phytoanticipins) or induced (phytoalexins). Typical phytoalexins of the family Fabaceae are isoflavonoid derivatives, with pterocarpan being the most abundant isoflavonoid skeleton (9). Different tissues of soybean (Glycine $\max$ L.) plants can produce the pterocarpan phytoalexin glyceollin in response to attack by various pathogens, such as Fusarium virguliforme, Heterodera glycines, and Phytophthora sojae $(6,10,15,22,27,32,35)$. Glyceollin is the collective name for soybean phytoalexins possessing pterocarpanoid skeletons and cyclic ether decoration originating from a C5 prenyl moiety. Three isomers of glyceollin (I, II, and III), which arise from the common precursor glycinol, were described in infected or stressed soybean plants and their relative proportions may vary depending on plant organ, the reaction type, and environment. Glyceollin I was found to be predominant in etiolated tissues (6). Results of in vitro tests with glyceollin-amended potato dextrose agar indicated significant growth inhibition for several soybean pathogens, including Cercospora sojina, Diaporthe phaseolorum var. meridionales, Macrophomina phaseolina, P. sojae, Sclerotinia sclerotiorum, Phialophora gregata, and Rhizoctonia solani (32).

The biosynthesis of glyceollin occurs via the isoflavonoid branch of the phenylpropanoid pathway. Enzymes involved in the biosynthesis of soybean isoflavones are formed during early stages of flavonoid production in the phenylpropanoid biosynthesis pathway. Genes encoding enzymes involved in isoflavonoid and glyceollin biosynthesis have been identified and cloned $(9,41,46)$. Several genes controlling later biosynthetic steps have 
recently been identified; in particular, the penultimate gene of glyceollin biosynthesis encoding a pterocarpan-specific prenyltransferase (dimethylallyltransferase), responsible for the addition of the dimethylallyl chain to pterocarpan (3).

With plant transformation, the involvement of phytoalexins and phytoanticipins in innate immune defense has been demonstrated in different plant species. Reduction or increase of the natural antimicrobial or antiherbivore compound concentrations in plant tissues via genetic engineering resulted in decreased or enhanced resistance to pathogens, respectively, in different host-pathogen systems $(1,7,11,18,19,23,24,31)$.

In our previous studies using the soybean hairy root model system, we showed that the soybean phytoalexin glyceollin was involved in resistance to a variety of soilborne soybean pathogens (27-29,31). Transformed hairy root lines containing either soybean isoflavone synthase (IFS2) or chalcone synthase (CHS6) genes in sense orientations, designed to reduce endogenous gene expression through post-transcriptional gene silencing, had significantly lower levels of the isoflavone daidzein, the precursor of glyceollin, compared with the nontransformed hairy root control lines. When these transformed hairy roots were inoculated with the soybean pathogens D. phaseolorum var. meridionales, M. phaseolina, Phytophthora sojae, and S. sclerotiorum, they produced significantly lower levels of glyceollin in response to inoculation (32). Consequentially, colonization by M. phaseolina, $P$. sojae, and S. sclerotiorum was correspondingly higher on IFS2sense and CHS6-sense transformed roots than on control roots, whereas colonization by $D$. phaseolarum var. meridionales was not significantly different from nontransformed control hairy roots. These results provided evidence that rapid glyceollin biosynthesis during infection may be an important component of innate disease resistance in soybean.

In this study, we describe the effects of isoflavone synthesis suppression on susceptibility to soybean pathogens through genetic manipulations in either the whole soybean plant or just in the seed. We used soybean line 51, previously generated in our group and described by Zernova et al. (49), that was transformed with the phenylalanine ammonia lyase (PAL5), CHS6, and IFS2 genes in sense orientation, driven by the seed-specific lectin promoter, and contained very low concentrations of isoflavones in seed compared with nontransformed plants. In addition, we tested a newly generated soybean line transformed with the IFS2 gene in sense orientation driven by the Cassava vein mosaic virus (CsVMV) constitutive promoter, and results presented here indicated significant suppression of isoflavone accumulation in the whole plant.

\section{MATERIALS AND METHODS}

Plant material. Four-month-old embryogenic cultures initiated from immature 'Jack' soybean cotyledons and grown on MSD-20 medium were bombarded with a mixture of expression cassettes, using a Biolistic PDS-1000 helium gun (Bio-Rad, Richmond, CA) as previously described (49). To obtain constitutive expression of the soybean IFS2 gene (accession number AF135484, 1.56 $\mathrm{kb}$ ), a 3.7-kb fragment cut with EcoRV from the plasmid pILTAB357 (The Scripps Research Institute, Division of Plant Biology, La Jolla, CA), containing the CsVMV promoter (47) and nos terminator, in which the IFS2 gene was inserted in sense orientation in the BamHI restriction site, as described in Lozovaya et al. (29), was used to bombard the soybean embryogenic cultures. The polymerase chain reaction (PCR) thermocycler programs and primers for the IFS2 and hygromycin phosphotransferase (HPT) genes, as well as all details of the DNA and RNA extraction and analysis procedures, Southern blot hybridization, and reversetranscriptase (RT)-PCR analysis, were described in detail in previous publications $(29,49)$. PCR amplification for each transgene presence was carried out using 10 plants of each transgenic line in four generations to test gene segregation in progeny and then 50 plants of the $T_{4}$ generation were PCR tested. The line that showed the transgene presence in the genome of all plants tested was determined to be homozygous. To select transformed cultures, we also used for bombardment the HPT gene expression cassette with the Cauliflower mosaic virus (CaMV) 35S promoter and nos terminator. Embryogenic cultures that survived the selection on medium containing hygromycin were transferred to plant regeneration medium (14).

RT-PCR analysis. Seeds of line 51 homozygous for transgenes and nontransformed Jack were surface sterilized using $20 \%$ commercial bleach solution for $20 \mathrm{~min}$ followed by germination on $1 \%$ sucrose and $1 \%$ agar medium. Total genomic RNA was extracted from germinated seed of line 51 at stages 1, 2, and 3, and also from roots, stems, and leaves of line 13 seedlings using RNasy Plant Mini Kit (Qiagen) and Rnase Free Dnase Set kit (Qiagen) to digest DNA during the RNA extraction. The RT reaction was performed using the One-Step RT-PCR kit (USB, Cleveland). A $10 \%$ portion of the RT reaction was used in PCR with primer pairs designed to amplify DNA containing the target genes and with Taq DNA polymerase (New England Biolabs, Inc., Beverly, MA).

PCR amplification of a 740-bp DNA fragment containing the soybean IFS2 gene was used to monitor IFS2 transgene expression in different tissues by the RT reaction. PCR primers were designed from the $5^{\prime}$ untranslated region of the lectin promoter (TGA CTC CCC ATG CAT CAC AG) or CsVMV promoter (AGG ATA CAA CTT CAG AGA) and 3' primers in the coding region of target gene in sense orientation: IFS2-736: TCG ATC CTC TTC TCA TAC TTT CCA ACC TTG AGA. This approach enabled us to measure the transgene message and not the message of the endogenous gene that has a different $5^{\prime}$ untranslated region. This approach was used to differentiate the expression of eight different soybean $C H S$ genes by Tuteja et al. (42). RT-PCR primers for the endogenous IFS 2 gene were used as a positive control for the seed analyses (data not shown) and were also used as a negative control in RT-PCR prepared using extracted RNA treated with DNaseI to avoid DNA contamination with Taq DNA polymerase but without the reverse transcriptase (data not shown).

Analysis of phenolic compounds. The content of phenylpropanoid compounds was measured separately in each leaf, stem, or root of homozygous transgenic and nontransformed plants. Multiple plants (five to seven replicates) of each test line were grown in the greenhouse. Nontransformed control plants and transgenic plants were grown in the same pots because previous results indicated that spatial environmental variability influenced levels of isoflavone concentration in soybean seed (31). Samples of seed, stems, and leaves were freeze dried and ground, and soluble phenolic compounds were extracted and then analyzed by high-performance liquid chromatography (HPLC), as previously described $(27,28)$. Preparation and HPLC analysis of soluble and cell-wall-bound phenolic acids are described by Lozovaya et al. $(26,30)$. Acetyl bromide lignin measurements were carried out as described (33).

Evaluation of the effects of pathogen colonization on plant phenolic compounds. Transgene homozygote lines 13 and 51 and nontransformed Jack soybean were used to determine the concentrations of phenolic compounds after inoculation with $P$. sojae and $M$. phaseolina in the same experiments using the same plants. These particular lines were selected from 27 transgenic lines screened for isoflavone levels in comparison with the nontransformed controls from the set of 10 transgenic lines which contained $<50 \%$ of the isoflavone levels of the control lines.

Plants were grown in 48-pot plastic inserts (number 1204; Hummert International) and thinned to one plant per pot after plant emergence. Each insert, with 12 rows of four pots, was filled with soil-less mix (Sunshine Mix, LC1; Sun Gro Horticulture Inc.), placed inside a flat with drainage holes (number 


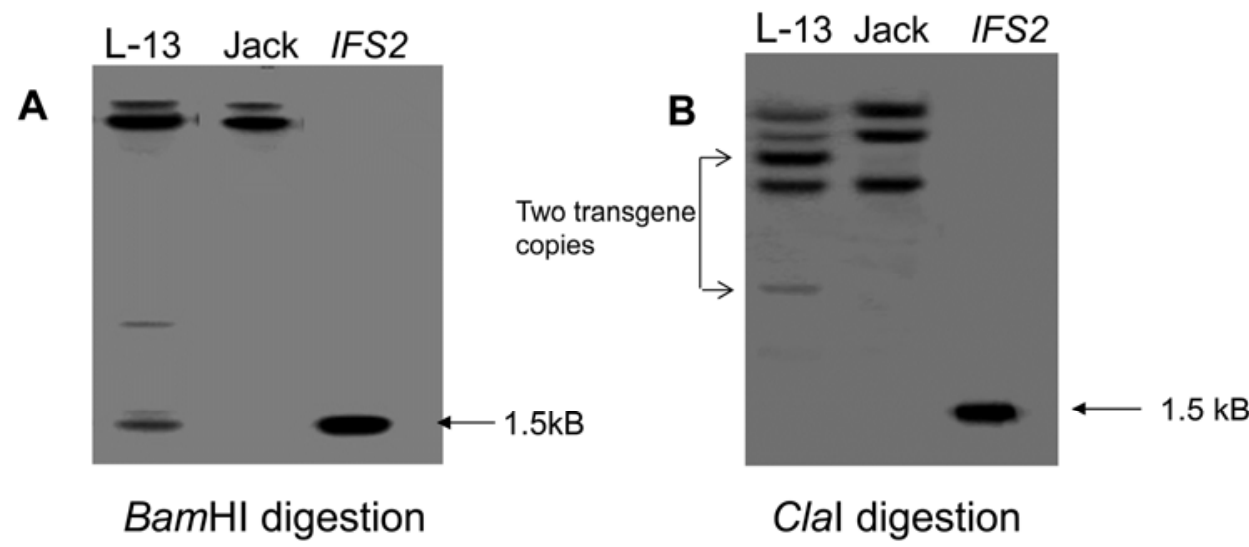

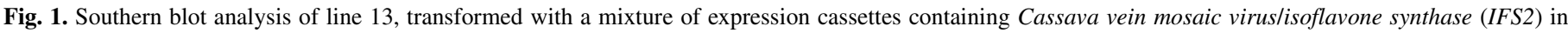

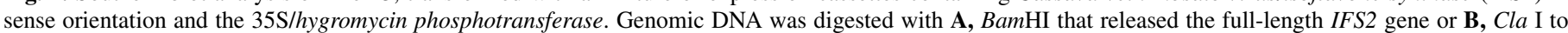

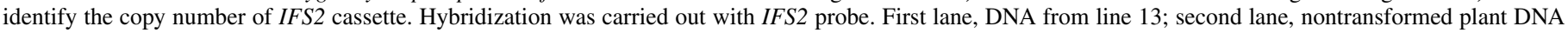
('Jack'); third lane, IFS2 cDNA.

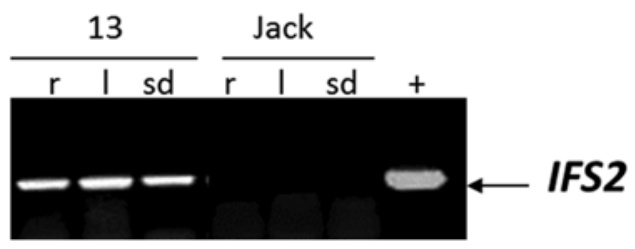

Fig. 2. Reverse-transcriptase polymerase chain reaction (PCR) with RNA, extracted from root, leaf, and developing seed from line 13 transformed with a mixture of cassettes-Cassava vein mosaic virus (CsVMV)/isoflavone synthase (IFS2) with gene in sense orientation and 35S/hygromycin phosphotransferase-and from nontransformed plant ('Jack'). Primers for the 5' untranslated part of the CsVMV promoter and the IFS2 were used. Abbreviations: $r=$ root, $1=$ leaf, $s d=$ seed; + indicates PCR with DNA extracted from transformed plant.

T1020; Hummert International), and fertilized at planting with slow-release pellets (Osmocote $19-6-12 ; 1$ to 2 pellets $/ \mathrm{cm}^{2}$ ). The experimental design was a randomized complete block with three replications or blocks. The experimental unit was four plants of each line planted in a row of four pots.

To determine biochemical changes caused by $P$. sojae infection, cotyledons were detached from 10 1-week-old seedlings of each plant of lines 13 and 51 and nontransformed Jack in the experiment and inoculated with $P$. sojae race 1 . The detached cotyledons of control and transgenic plants were first transferred to moist blotting paper placed inside 8.5 -cm-diameter plastic petri dishes. Then, a few cuts were aseptically done on the cotyledon surface with a new, sterile, sharp scalpel blade, prior to placing potato dextrose agar (PDA) plugs with $P$. sojae, cut from the margin of 5-day-old V8A cultures on the cotyledons. As a negative control, PDA plugs without $P$. sojae were placed on 10 additional cotyledons of each line. The cotyledons were kept in the dark at room temperature, $\approx 22^{\circ} \mathrm{C}$. Samples from the inoculated and control cotyledons were collected at 24, 48, and $72 \mathrm{~h}$ postinoculation for biochemical analysis.

To measure the effect of $M$. phaseolina colonization on transgenic lines 13 and 51 in comparison with nontransformed Jack soybean, a cut-stem inoculation technique was used (43). V2stage plants in the experiment were inoculated using the cut-stem technique and the extent of necrosis from the inoculation point was measured $72 \mathrm{~h}$ after inoculation and incubation in a greenhouse maintained at $30^{\circ} \mathrm{C}$. An M. phaseolina isolate labeled Mp3 that was collected in Urbana, IL was used in this test. Healthy stem and necrotic tissue below the apical inoculation point were sampled for biochemical analysis.

For evaluating the response of the transgenic lines to $P$. sojae, an agar layer test was used (13). Transgenic Jack line 13 and

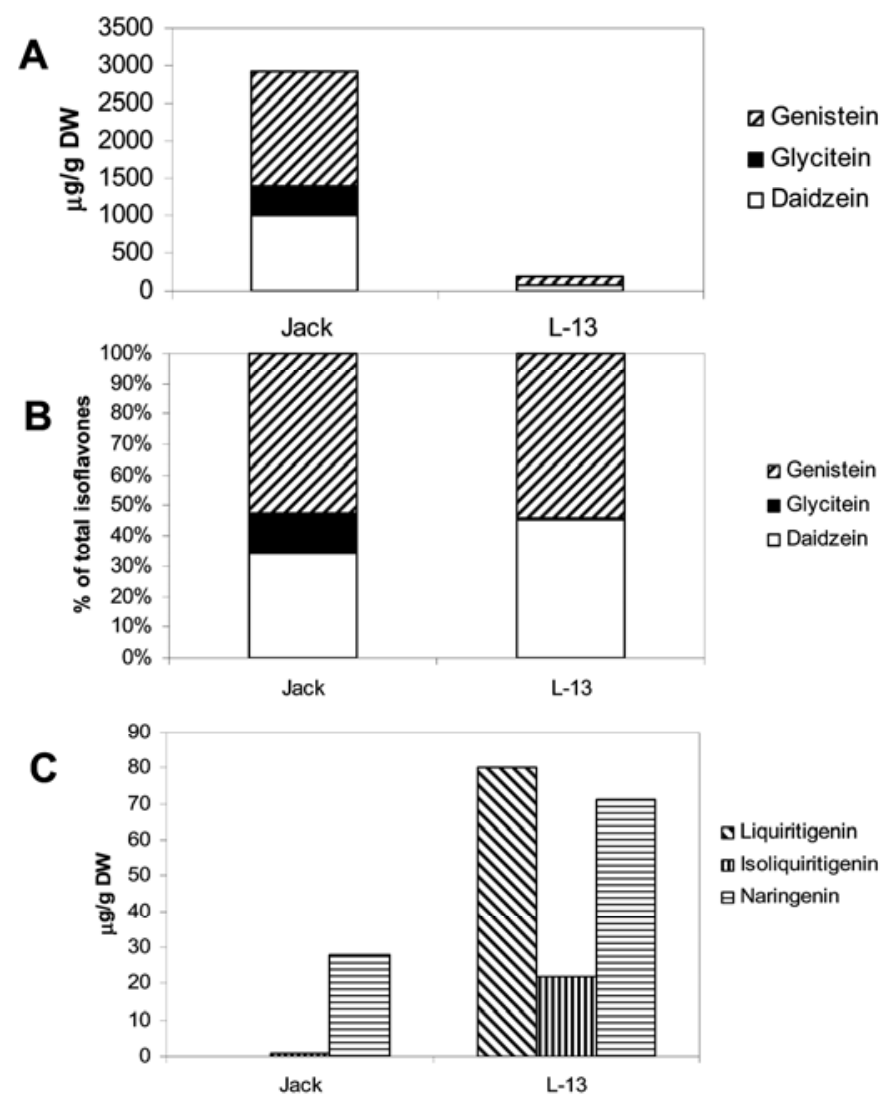

Fig. 3. Isoflavonoids in whole soybean seed of 'Jack' and line 13: A, concentration of isoflavones; $\mathbf{B}$, proportion; and $\mathbf{C}$, concentration of isoflavone precursors.

nontransgenic Jack were planted into plastic cups containing fine silica sand inoculated with a V8-10 agar culture of $P$. sojae race 1 placed approximately in the middle of each cup prior to sowing. Three replicate cups of each soybean line were planted. Three weeks after planting, the plants were removed from the pots and the roots were washed free of sand and examined for root symptoms.

In another experiment, soybean radicals were evaluated for colonization by $M$. phaseolina after inoculating with conidia following the procedures of Ma et al. (34). Conidia produced by an M. phaseolina isolate from Pinetree, AR were suspended in sterile, distilled water. Inoculum was quantified and diluted to 

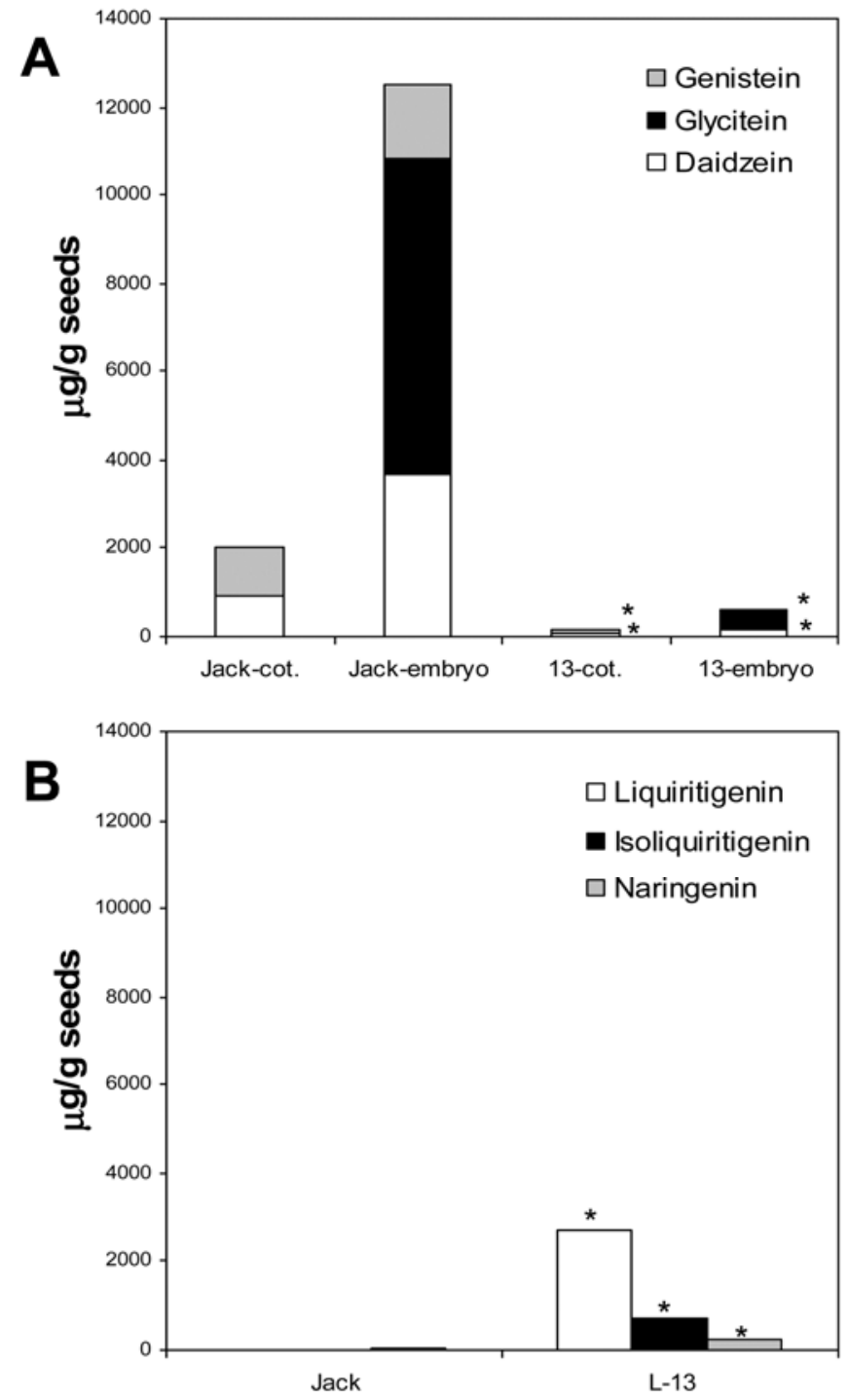

Fig. 4. Concentration of isoflavonoids in different parts of 'Jack' and line 13 soybean seed: $\mathbf{A}$, isoflavones in cotyledons and embryo axes and $\mathbf{B}$, precursors of isoflavones in embryo axes; * indicates significant differences between transformants and control $(P \leq 0.05)$.

deliver $\approx 500$ conidia to each inoculated radicle in a $10-\mu$ drop. At $72 \mathrm{~h}$ after inoculation and incubation at $28^{\circ} \mathrm{C}$, necrotic lesion lengths were measured.

Statistical analysis. Statistical analysis of metabolite data was done by one-way analysis of variance and $t$ test, using the algorithm incorporated into Microsoft Excel 2010 (Microsoft Corp., Seattle, WA). Differences were confirmed to be statistically significant at $P<0.05$.

\section{RESULTS AND DISCUSSION}

Molecular and biochemical characterization of constitutive expression of the IFS 2 gene in transgenic soybean. Soybean transgenic line 13, selected from a collection of transgenic soybean plants generated through bombardment of embryogenic cultures with transformation cassettes containing the IFS2 gene and the selectable marker HPT gene, showed very low isoflavone content in $\mathrm{T}_{0}$ generation plants. Southern blot analysis of the genomic DNA of line 13 plants homozygous for the IFS2 transgene showed the presence of the full-length IFS2 transgene with BamHI restriction enzyme (used for gene cloning), and a single cutter restriction enzyme, ClaI, showed the presence of two transgene copies (Fig. 1A and B).
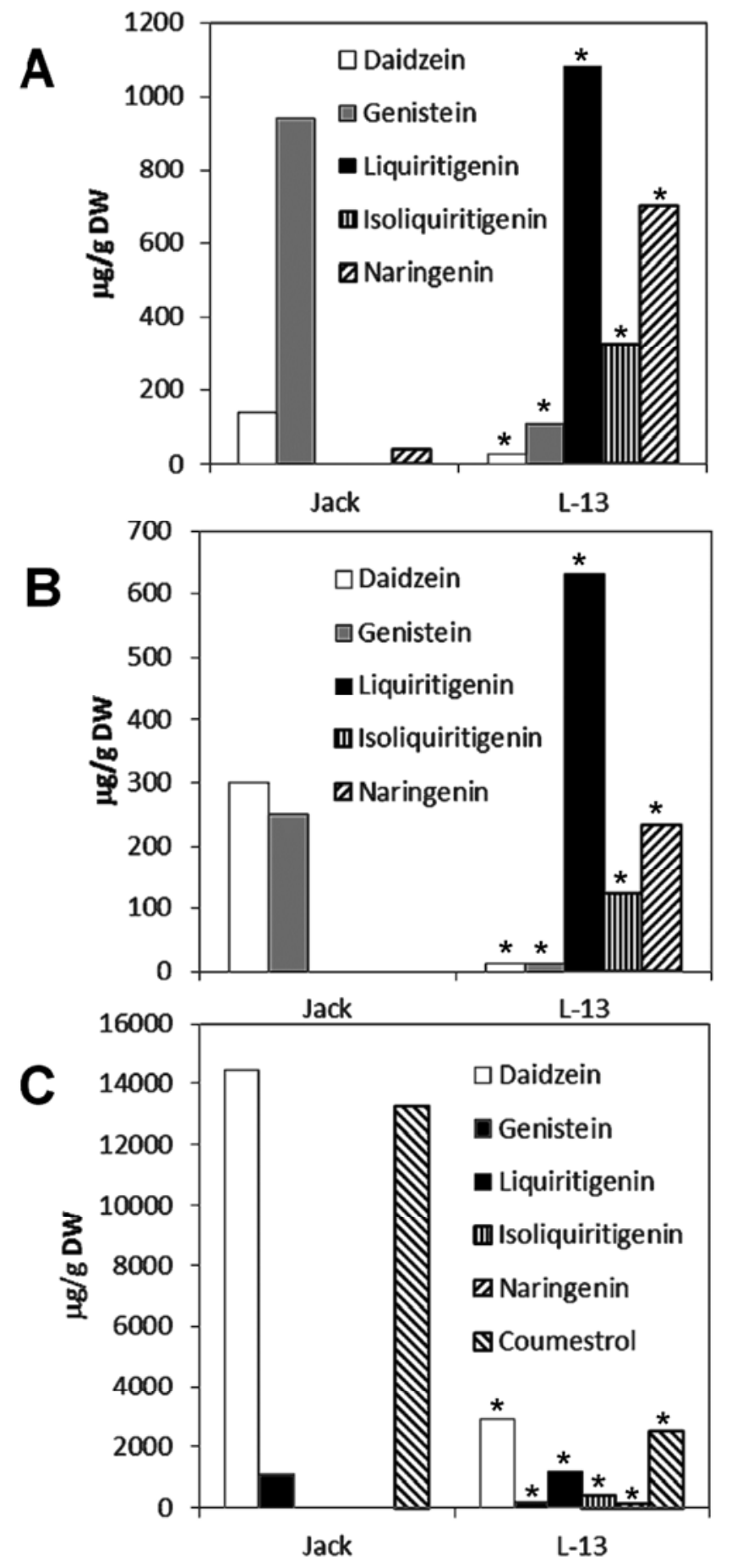

Fig. 5. (Iso)flavonoid concentrations in the control 'Jack' and transgenic line 13 in A, leaves; B, stems; and $\mathbf{C}$, roots; * indicates significant differences between transformants and control $(P \leq 0.05)$.

RT-PCR showed the expression of the IFS2 transgene in roots, leaves, and seed of this line of plants (Fig. 2). Changes in phenylpropanoids caused by expression of the IFS2-sense transgene under the constitutive promoter were determined in seed, leaves, and roots of line 13 plants in comparison with nontransformed plants. Total accumulation of all three main soybean isoflavones (genistein, daidzein, and glycitein) in the transformed plants was significantly lower than the nontransformed control, although relative proportions of each isoflavone were not changed (Fig. 3A and $\mathrm{B})$. Concentration of isoflavone precursors in transformed seed was several-fold higher than nontransformed seed (Fig. 3C). These results with high probability indicated that post-transcrip- 
tional silencing with homologous IFS2 DNA occurred in these plant tissues. Similar effects were previously found in our studies with transformed hairy roots (29).

It has to be pointed out that, in our previous studies, when transgenes were driven by the cotyledon-specific lectin promoter, inhibition of only daidzein and genistein synthesis occurred whereas glycitein synthesis, which primarily took place in the embryo axis and not in the cotyledon (Fig. 4A), was not influenced by the transgene expression (49). We found accumulation of isoflavone precursors in the embryo axes of line 13 transgenic seed, with isoliquiritigenin, a putative precursor of glycitein (25) accumulating to a higher level than the nontransformed control (Fig. 4B).

The major isoflavone of soybean roots in plants tested was daidzein, whereas genistein was the major isoflavone in soybean leaves and approximately equal concentrations of these two isoflavones were present in stems (Fig. 5). Glycitein was not detected in roots, stems, or leaves, as we also previously reported (33). Both daidzein and genistein concentrations were severalfold lower in leaves, stems, and roots in plants of transgenic line 13 compared with the nontransformed control plants; instead, these transgenic plants accumulated high levels of isoflavone molecular precursors (Fig. 5A to C). Lower levels of isoflavone concentrations in transgenic plants were concomitant with higher accumulation of isoflavone precursors and also with a greater flux of metabolites through the alternative branch of the phenylpropanoid pathway, leading to accumulation of hydroxycinnamic acids. Levels of both soluble and cell-wall-bound phenolics were higher in transgenic plants than in nontransformed plants (Fig. 6), although there was no difference in composition and proportion of these phenolic compounds. These changes in phenolic compounds were consistent with previously reported results of our studies with the soybean hairy-root model system (29).

Molecular and biochemical characterization of cotyledons of line 51 plants transformed with the IFS2 gene driven by the lectin promoter. The soybean seed lectin Le1 promoter has been shown to be seed-preferable $(8,38,39)$. In our previous studies, we found that the IFS2 gene driven by the Le1 promoter was highly expressed in cotyledons but not in the embryo axis of developing seed of line 51 plants, with a very low level of the IFS 2 expression detected in leaf and root tissues (49). These results confirmed
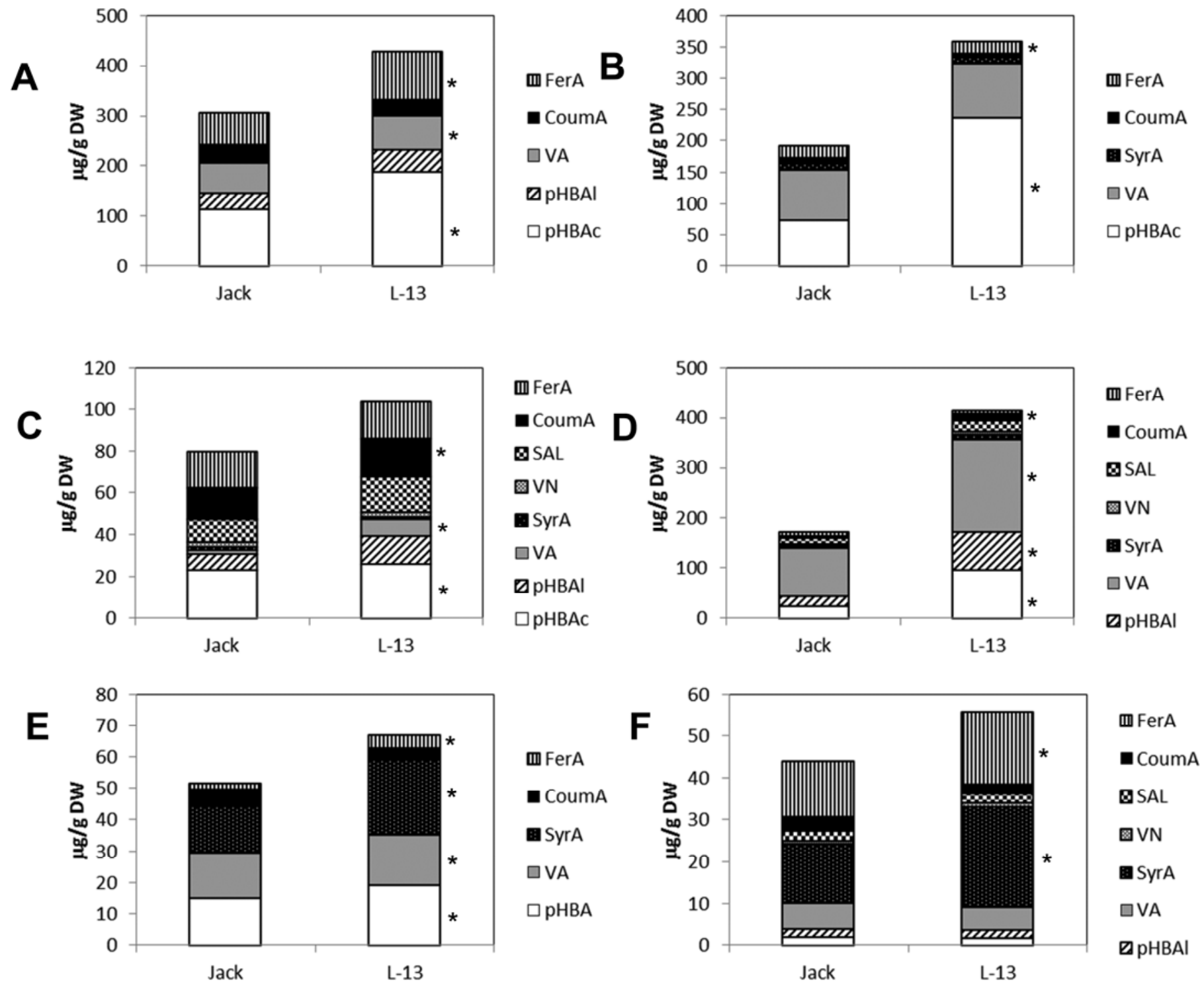

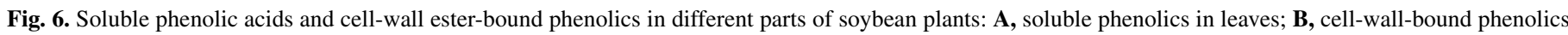

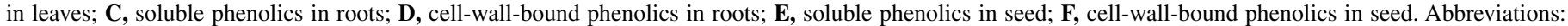

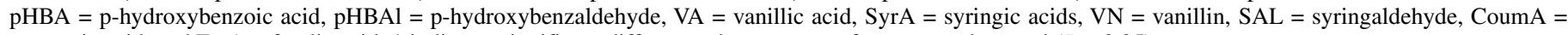
coumaric acid, and FerA = ferulic acid; * indicates significant differences between transformants and control $(P \leq 0.05)$. 
that the Le1 promoter is active specifically in seed tissues and not in other tissues.

In this study, we assayed the IFS2 transgene expression in line 51 during seed germination and seedling development (Fig. 7). Interestingly, isoflavone synthesis appeared to be nearly completely suppressed in young emergent cotyledons of transgenic plants compared with the nontransformed control plants during the 10-day observation period whereas the precursors of isoflavone synthesis accumulated, with their concentration gradually increasing over time in the transgenic cotyledons. RT-PCR results confirmed the expression of the IFS 2 in cotyledons at these early stages of seedling development (Fig. 7). Reduced $\beta$-glucuronidase activity when driven by soybean seed lectin L1 promoter was previously reported in the cotyledons and hypocotyl of developing transgenic Arabidopsis seedlings for $\approx 5$ days after being placed in the growth chamber (40). Even though we did not find any notable changes in phenolic metabolism of soybean vegetative tissues in older established transgenic plants transformed with the genes driven by the L1 seed lectin promoter, the question arises of whether such dramatic modifications of phenolic metabolism in cotyledons at very early stages of transgenic seedling development could affect plant growth and seedling disease resistance.

Testing of homozygous transgenic lines 13 and 51 for response to soybean pathogens. Transgenic line 51, previously described by Zernova et al. (49), and newly generated line 13 (described above) were used to test their response to infection by the soybean pathogens $M$. phaseolina and P. sojae.

Response of transgenic plants to $\boldsymbol{P}$. sojae infection. We used the detached soybean cotyledon assay developed by Graham et al, $(16,17)$ to test the biochemical response of 10-day-old transgenic plants of lines 51 and 13 to $P$. sojae. Noninoculated cotyledons of both transgenic lines had $\approx 5$ - to 10 -fold lower genistein and daidzein concentrations than noninoculated, nontransformed control plants (Fig. 8). Changes in isoflavonoid levels in cotyledons of nontransformed and transgenic plants were analyzed 24 and $72 \mathrm{~h}$ after inoculation with $P$. sojae (Figs. 8 and 9). Results indicated that isoflavone levels in noninoculated and inoculated cotyledons of nontransformed plants did not substantially differ after $24 \mathrm{~h}$ after inoculation; however, isoflavone levels significantly increased in noninoculated, nontransformed cotyledons, whereas

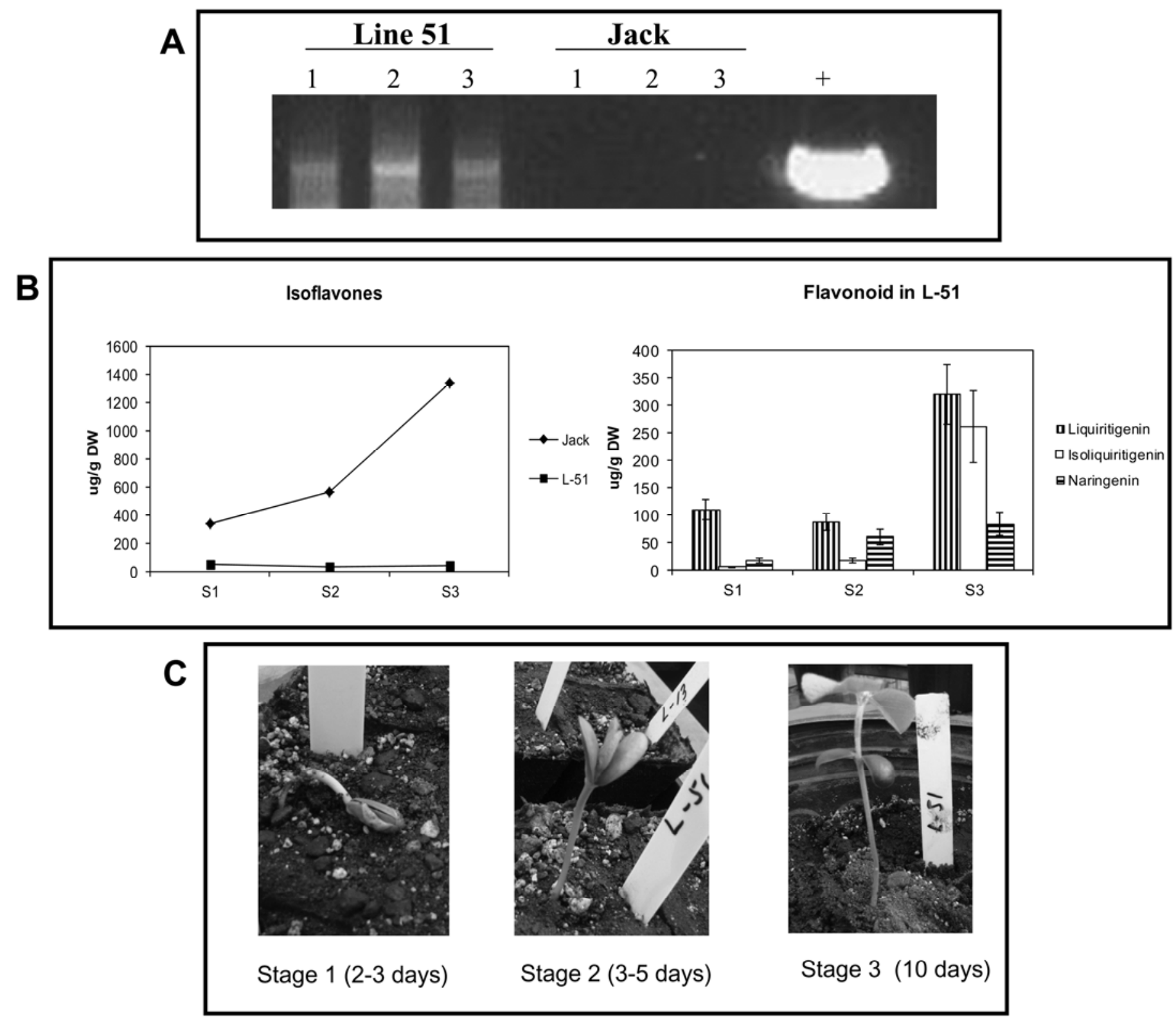

Fig. 7. Effect of the isoflavone synthase (IFS2) gene expression (A) when controlled by soybean L1 promoter on phenolic metabolism (B) in soybean cotyledons or emerging seedlings $(\mathbf{C})$. 
there were no marked changes in isoflavone level in inoculated nontransformed cotyledons $72 \mathrm{~h}$ after inoculation (Fig. 8). There were trends observed in transgenic cotyledons, with the isoflavone concentrations approximately an order of magnitude less than in nontransformed cotyledons. Accumulation of the phytoalexin glyceollin occurred only in the $P$. sojae-inoculated, nontransformed cotyledons (Fig. 9). It was not detected $24 \mathrm{~h}$ after inoculation in noninoculated, nontransformed cotytledons. Glyceollin was present in noninoculated, nontransformed cotyledons $72 \mathrm{~h}$ after inoculations at concentrations several-fold lower that of inoculated cotyledons. Induction of glyceollin biosynthesis in detached nontransformed cotyledons could be caused by wounding and by $P$. sojae infection. Nevertheless, glyceollin concentration was much higher in inoculated than noninoculated cotyledons, especially with increasing time after inoculation, demonstrating the induction of glyceollin biosynthesis by $P$. sojae infection.

Isoflavone precursors accumulated in cotyledons of both transgenic lines 13 and 51, with higher concentrations found in line 13, where the IFS2 transgene was driven by the constitutive CaMV 35S promoter. There were differences between the transgenic lines in the concentrations and ratio of precursors, possibly caused by the expression of two other genes of phenolic metabolism, PAL5 and CSH6, in line 51 but not in line 13, in addition to the IFS2 gene (49). Reduction of glyceollin accumulation in transgenic cotyledons with suppressed isoflavone synthesis, infected with $P$. sojae, led to greater observed cotyledon damage (data not shown).

We also inoculated untransformed plants and plants of line 13 with $P$. sojae and found severe damage of transgenic plants compared with the nontransformed Jack plants 21 days after planting (Fig. 10).

Response of transgenic plants to $M$. phaseolina infection. Using the cut-stem inoculation technique (43), the mean length of necrosis of nontransformed Jack plants was $26.6 \pm 3.4 \mathrm{~mm}$, whereas it was $34.6 \pm 2.5 \mathrm{~mm}$ for line 13 and $32.0 \mathrm{~mm}$ for line 51 plants. There also were significantly longer lesions on radicles of the transgenic line 13 compared with nontransformed controls (Fig. 11).

These results indicated the increased susceptibility of line 13 to $M$. phaseolina colonization compared with the nontransformed plants Jack and transgenic line 51 expressing transgenes only in seed.

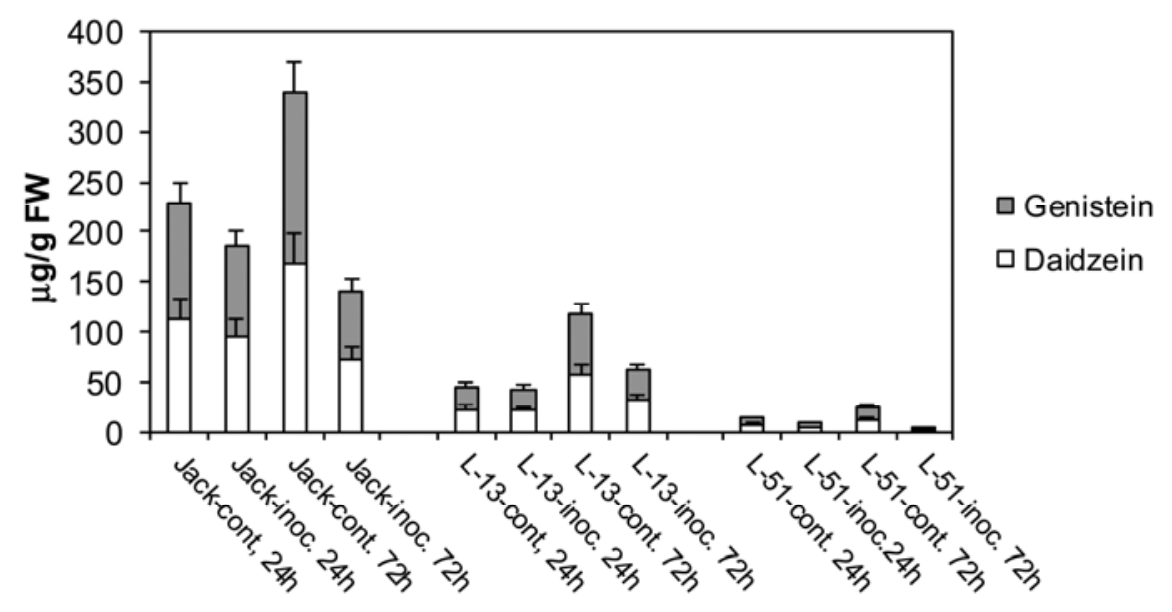

Fig. 8. Isoflavones, daidzein, and genistein in detached cotyledons of 10-day-old soybean plants 24 and $72 \mathrm{~h}$ after inoculation with Phytophthora sojae race 1.
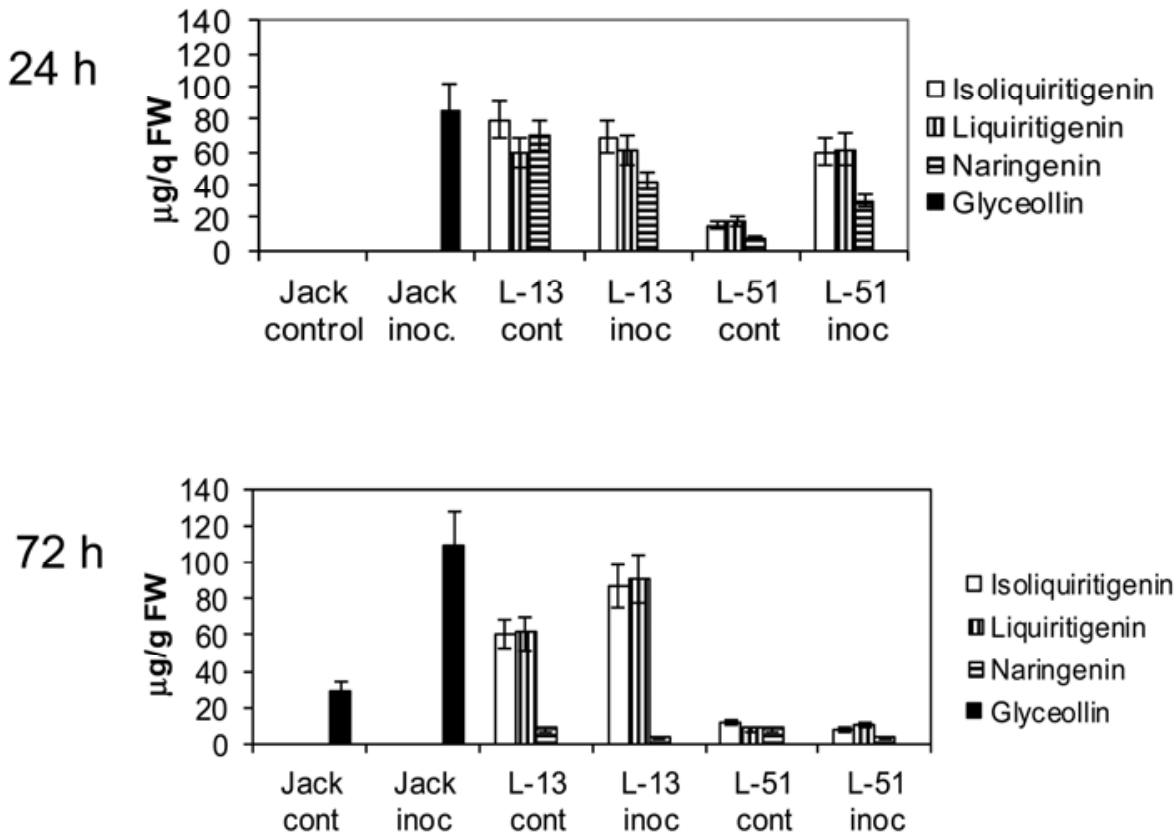

Fig. 9. Isoflavone precursors, naringenin, liquiritigenin, isoliquiritigenin, and phytoalexin glyceollin in detached cotyledons of 10-day-old soybean plants 24 and $72 \mathrm{~h}$ after inoculation with Phytophthora sojae race 1. 
Stem segments of these plants infected with $M$. phaseolina were used for soluble and cell-wall-bound phenolic analysis 24 and $72 \mathrm{~h}$ after inoculation (Figs. 12 to 14). Both inoculated and noninoculated line 51 and nontransformed control plants had similar patterns of isoflavone, flavonoid, and cell-wall-bound phenolic contents $24 \mathrm{~h}$ after inoculation. This pattern persisted $72 \mathrm{~h}$ after inoculation. Only traces of isoflavones and glyceollins were detected in line 13 stems, with the IFS2-sense gene driven by the $35 \mathrm{~S}$ constitutive promoter, whether inoculated or not, indicating strong suppression of the biosynthesis of those compounds. Further evidence of strong suppression was found in the higher accumulation of isoflavone precursors and cell-wall-bound phenolics in plants of line 13 compared with nontransformed control plants. This accumulation was probably due to silencing of the

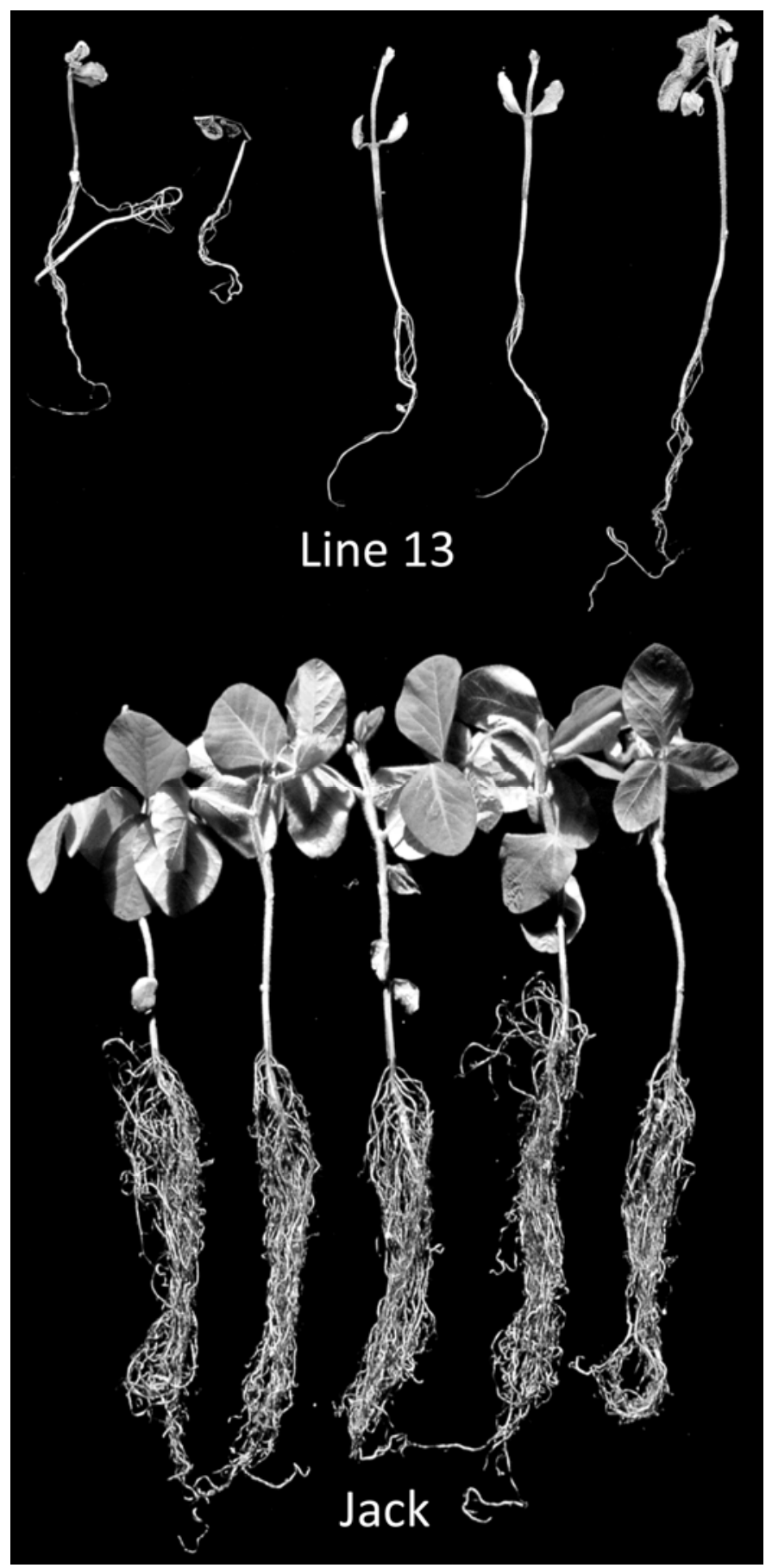

Fig. 10. 'Jack' and transgenic plants line 13 at 21 days after inoculation with Phytophthora sojae race 1. endogenous IFS2 gene through interference in translation by the transcript of the transgenic IFS2-sense gene.

Lignin content increased equally in stems of both nontransformed and transgenic lines 13 and 51 in response to M. phaseolina infection (Fig. 15). However, there was no difference in lignin concentration measured between stem samples compared.

Conclusion. Results in this study clearly demonstrated a significant reduction of phytoalexin glyceollin production in transgenic lines transformed with a gene that suppresses glyceollin biosynthesis. These results are consistent with previously reported studies describing similar suppression of isoflavone synthesis and, related to this, markedly reduced root capacity to produce glyceollin and increased susceptibility to pathogen infection in many independent soybean hairy root lines (used as a model system) transformed with the same transgenes $(27-29,31)$. The effect of reduced glyceollin accumulation led to increased susceptibility to

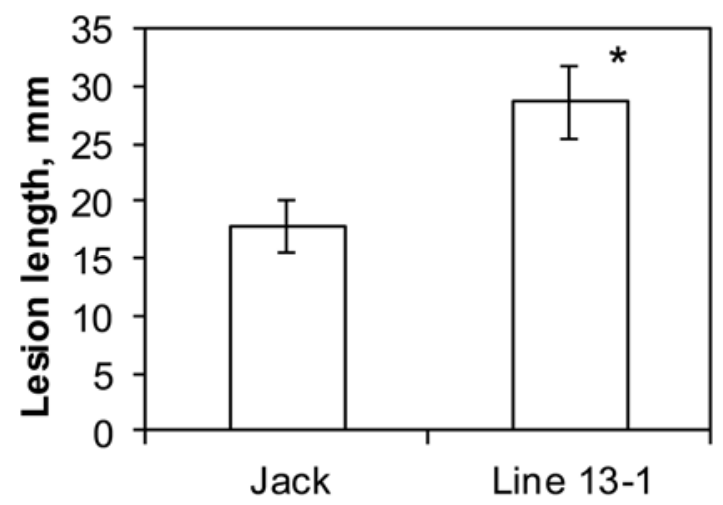

Fig. 11. Colonization of soybean radicals by Macrophomina phaseolina.
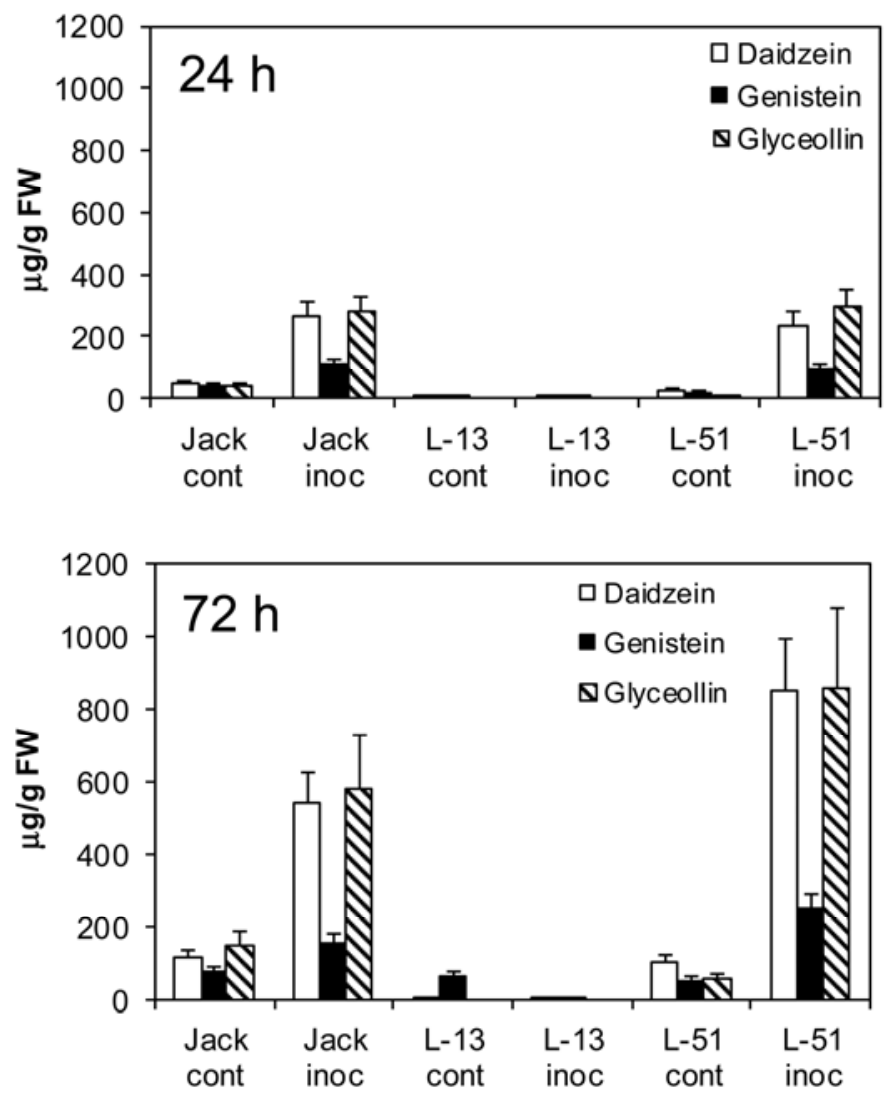

Fig. 12. Concentrations of daidzein, genistein, and phytoalexin glyceollins in stems of 14-day-old soybean plants 24 and $72 \mathrm{~h}$ after inoculation with Macrophomina phaseolina. 
$24 \mathrm{~h}$

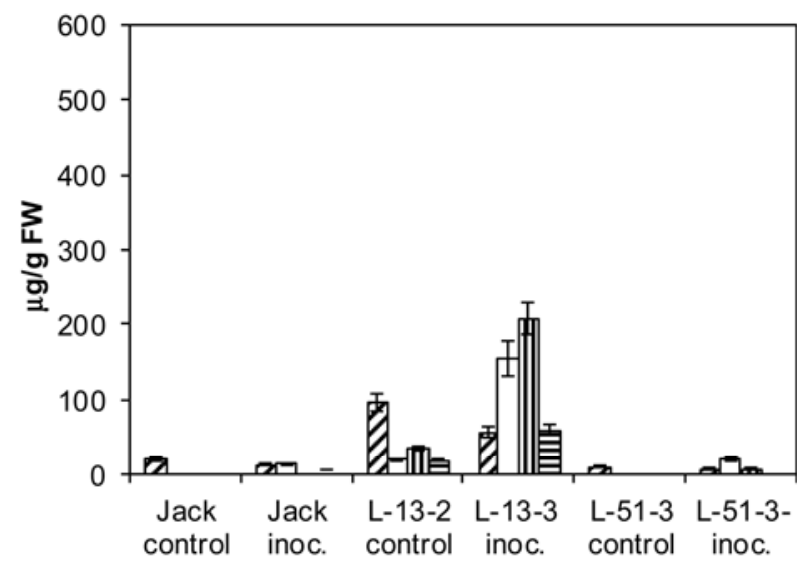

¿ Kaempferol

$\square$ Isoliquirotigenin

س Liquiritigenin

ENaringenin

$72 \mathrm{~h}$

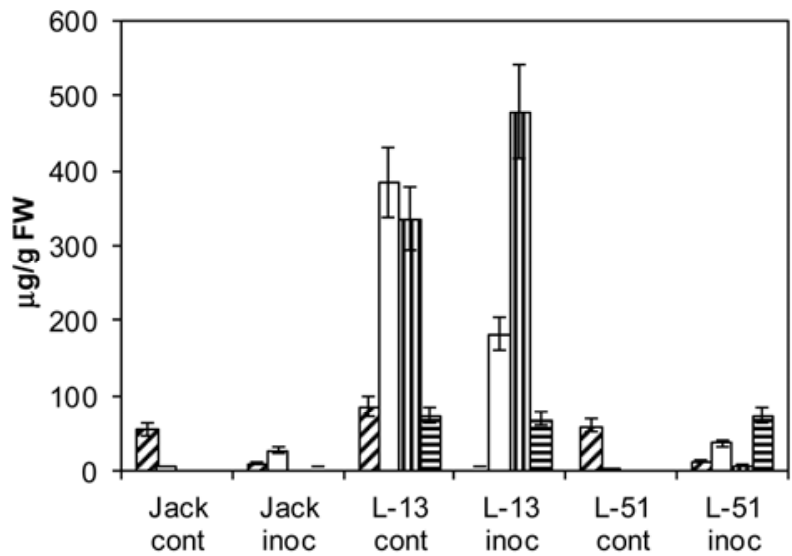

aKaempferol

$\square$ Isoliquirotigenin

w Liquiritigenin

a Naringenin

Fig. 13. Isoflavone precursors, naringenin, liquiritigenin, isoliquiritigenin, and flavonol kaempferol in stems of 14-day-old soybean plants 24 and $72 \mathrm{~h}$ after inoculation with Macrophomina phaseolina.

$24 \mathrm{~h}$

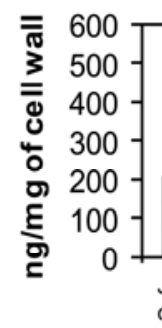

$72 \mathrm{~h}$

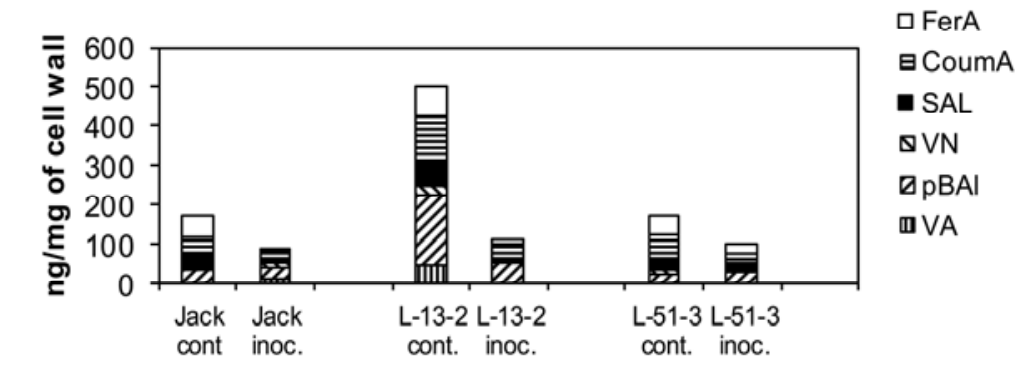

Fig. 14. Cell-wall-bound phenolics in stems of 14-day-old soybean plants 24 and $72 \mathrm{~h}$ after inoculation with Macrophomina phaseolina: VA $=$ vanillic acid, $\mathrm{pBAl}=\mathrm{p}$-hydroxybenzaldehyde, $\mathrm{VN}=$ vanillin, $\mathrm{SAL}=$ syringaldehyde, CoumA = coumaric acid, and FerA = ferulic acid.

two soybean pathogens compared with nontransformed control plants. This result supports the hypothesis that rapid glyceollin accumulation during infection contributes to the innate soybean defense response.

No sources of complete resistance in soybean or in other plant species have been found for a number of soybean pathogens, such as $M$. phaseolina (causing charcoal rot), S. sclerotiorum (causing Sclerotinia stem rot), and $F$. virgiliforme (causing sudden death syndrome). These pathogens, and potentially all other pathogens that are generalists, appear to have the capacity to avoid recognition by host resistance genes that recognize pathogen-associatedmolecular-pattern products. Partial resistance to these pathogens 


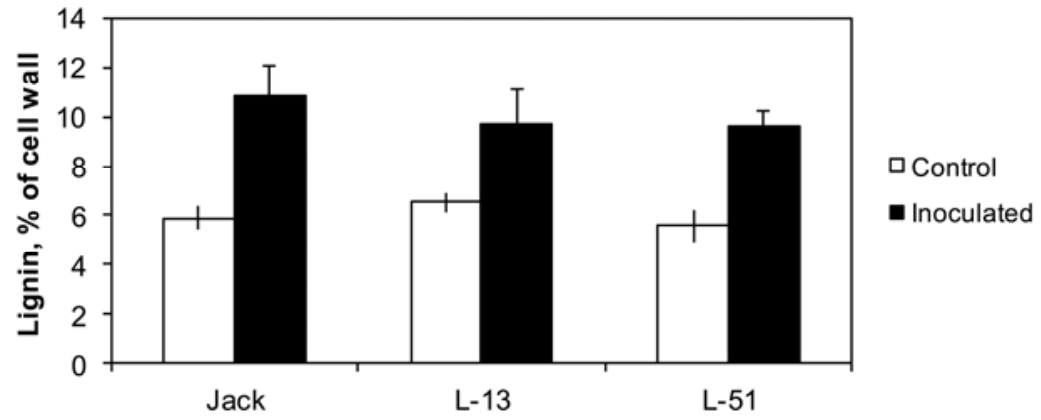

Fig. 15. Lignin in stems of 14-day-old soybean plants $72 \mathrm{~h}$ after inoculation with Macrophomina phaseolina.

has been reported but this kind of resistance has not been widely used to develop commercial soybean cultivars, possibly because of the low heritability associated with this kind of resistance. Variation in partial resistance in soybean genotypes may be due to variable innate resistance controlled by quantitative trait loci. Strengthening the innate defense system through genetic transformation may complement or exceed the capacity of genetic partial resistance. The demonstration of glyceollin suppression increasing susceptibility to two soybean pathogens in this study suggests that the genetic engineering of the phenylpropanoid pathway to increase the biosynthesis of glyceollin in different plant tissues could help improve the management of pathogens and possibly also pests.

\section{ACKNOWLEDGMENTS}

This work was supported, in part, by funds from the United Soybean Board, USB Project number 1272 and the United States Department of Agriculture Cooperative State Research, Education and Extension Service, Hatch project number ILLH-802-309 and 802-352. We thank L. Crull for technical help with inoculation of plant materials.

\section{LITERATURE CITED}

1. Aharoni, A., and Galili, G. 2011. Metabolic engineering of the plant primary-secondary metabolism interface. Curr. Opin. Biotechnol. 22:239244.

2. Ahuja, I., Kissen, R., and Bones, A. M. 2012. Phytoalexins in defense pathogens. Trends Plant Sci. 2:73-90.

3. Akashi, T., Sasaki, K., Aoki, T., Ayabe, S., and Yazaki, K. 2009. Molecular cloning and characterization of a cDNA for pterocarpan 4-dimethylallyltransferase catalyzing the key prenylation step in the biosynthesis of glyceollin, soybean phytoalexin. Plant Physiol. 149: 683-693.

4. Albersheim, P., and Valent, B. S. 1978. Host-pathogen interaction in plants. Plants, when exposed to oligosaccarides of fungal origin, defend themselves by accumulating antibiotics, J. Cell Biol. 78:627-643.

5. Bednarek, P., and Osbourn, A. 2009. Plant-microbe interactions: Chemical diversity in plant defense, Science 324:746-748.

6. Bhattacharyya, M. K., and Ward, E. W. B. 1985. Differential sensitivity of Phytophthora megasperma f. sp. glycinea to glyceollin isomers, Physiol. Mol. Plant Pathol. 27:299-310.

7. Campbell, M. A., Fitzgerald, H. A., and Ronald, P. C. 2002. Engineering pathogen resistance in crop plants. Transgenic Res. 11:599-613.

8. Cho, M.-J., Widholm, J., and Vodkin, L. 1995. Cassettes for seed-specific expression tested in transformed embryogenic cultures of soybean. Plant Mol. Biol. Rep. 13:255-269.

9. Dixon, R. A. 1999. Isoflavonoids: Biochemistry, molecular biology, and biological functions. Pages 778-823 in: Comprehensive Natural Products Chemistry, Vol 1. Polyketides and Other Secondary Metabolites Including Fatty Acids and Their Derivatives. U. Sankara, ed. Elsevier, Oxford.

10. Ebel, J., and Grisebach, H. 1988. Defense strategies of soybean against the fungus Phytophthora megasperma f. sp. glycinea: A molecular analysis. Trends Biochem. Sci. 13:23-27.

11. Essenberg, M. 2001. Prospects for strengthening plant defenses through phytoalexin engineering. Physiol. Mol. Plant Pathol. 59:71-81.

12. Eyles, A., Bonello, P., Ganley, R., and Mohammed, C. 2010. Induced resistance to pests and pathogens in trees: Review. New Phytol. 185:893908.
13. Ferro, C. R., Hill, C. B., Miles, M. R., and Hartman, G. L. 2006. Evaluation of soybean cultivars with the $R p s 1 k$ gene for resistance and tolerance to Phytophthora sojae. Crop Sci. 46:2427-2436.

14. Finer, J. J., and McMullen, M. D. 1990. Transformation of cotton (Gossypium hirsutum L.) via particle bombardment. Plant Cell Rep. 8:586589.

15. Graham, T. L. 1991. A rapid, high resolution performance liquid chromatography profiling procedure for plant and microbial aromatic secondary metabolites. Plant Physiol. 95:584-593.

16. Graham, T. L., and Graham, M. Y. 1991. Glyceollin elicitors induce major but distinctly different shifts in isoflavonoid metabolism and distal soybean cell populations. Mol. Plant-Microbe Interact. 4:60-68.

17. Graham, T. L., Kim, J. E., and Graham, N. Y. 1990. Role of constitutive isoflavones in accumulation of glyceollin in soybean infected with Phytophthora megasperma. Mol. Plant-Microbe Interact. 3:157-166.

18. Grobkinsky, D. K., van der Graaff, E., and Roitsch, T. 2012. Phytoalexin transgenics in crop protection-fairy tale with a happy end? Plant Sci. 195:54-70.

19. Hain, R., Reif, H. J., Krause, E., Langebartels, R., Kindl, H., Vornam, B., Wiese, W., Schmelzer, E., Schreier, P. H., Stocker, R. H., and Strenzel, K. 1993. Disease resistance results from foreign phytoalexin expression in a novel plant. Nature 361:153-156.

20. Hammerschmidt, R. 1999. Phytoalexins: What have we learned after 60 years. Annu. Rev. Phytopathol. 37:285-306.

21. Hartman, G. L., Sinclair, J. B., and Rupe, J. C. 1999. Compendium of Soybean Diseases. American Phytopathological Society, St. Paul, MN.

22. Huang, J. S., and Barker, K. R. 1991. Glyceollin in soybean-cyst nematode interactions. Plant Physiol. 96:1302-1307.

23. Jeandet, P.,. Delaunois, B., Conreux, A., Donnez, D., Nuzzo, V., Cordelier, S., Clement, C., and Courot, E. 2010. Biosynthesis, metabolism, molecular engineering and biological functions of stilbene phytoalexins in plants. Biofactors 36:331-341.

24. Jeandet, P., Douillet, A. C., Debord, S., Sbaghi, M., Bessis, R., and Adrian, M. 2002. Phytoalexins from the Vitaceae: Biosynthesis, phytoalexin gene expression in transgenic plants, antifungal activity, and metabolism. J. Agric. Food Chem. 50:2731-2741.

25. Latunde-Dada, A. O., Cabello-Hurtado, F., Czittrich, N., Didierjean, L., Schopfer, C., Hertkorn, N., Werck-Reichart, D., and Ebel, J. 2001. Flavonoid 6-hydroxylase from soybean (Glycine max L.), a novel plant P450 monooxygenase. J. Biol. Chem. 276:1685-1688.

26. Lozovaya, V., Ulanov, A., Lygin, A., Duncan, D., and Widholm, J. 2006. Biochemical features of maize tissues with different capacities to regenerate plants. Planta 224:1385-1399.

27. Lozovaya, V. V., Lygin, A. V., Li, S., Hartman, G. L., and Widholm, J. M. 2004. Biochemical response of soybean roots to Fusarium solani f. sp. glycines infection. Crop Sci. 44:819-826.

28. Lozovaya, V. V., Lygin, A. V., Zernova, O. V., Li, S., Hartman, G. L., and Widholm, J. M. 2004. Isoflavonoid accumulation in soybean hairy roots upon treatment with Fusarium solani. Plant Physiol. Biochem. 42:671679.

29. Lozovaya, V. V., Lygin, A. V., Zernova, O. V., Li, S., and Widholm, J. M. 2006. Lignin Degradation by Fusarium solani f. sp. glycines. Plant Dis. 90:77-82.

30. Lozovaya, V. V., Lygin, A. V., Zernova, O. V., Ulanov, A. V., Li, S., Hartman, G. L., and Widholm, J. M. 2007. Modification of phenolic metabolism in soybean hairy roots through down regulation of chalcone synthase or isoflavone synthase. Planta 225:665-679.

31. Lozovaya, V. V., Lygin, A. V., Zernova, O. V., and Widholm, J. M. 2005. Genetic engineering of plant disease resistance by modification of the phenylpropanoid pathway. Plant Biosyst. 139:20-23.

32. Lygin, A. V., Hill, C. B., Zernova, O. V., Crull, L., Widholm, J. M., Hartman, G. L., and Lozovaya, V. V. 2010. Response of soybean pathogens to glyceollin. Phytopathology 100:897-903. 
33. Lygin, A. V., Li, S., Vittal, R., Widholm, J. M., Hartman, G. L., and Lozovaya, V. V. 2009. The importance of phenolic metabolism to limit the growth of Phakopsora pachyrhizi. Phytopathology 99:1412-1420.

34. Ma, J., Hill, C. B., and Hartman, G. L. 20120. Production of Macrophomina phaseolina conidia by multiple soybean isolates in culture. Plant Dis. 94:1088-1092.

35. Paxton, J. D. 1975. Phytoalexins, phenolics and other antibiotics in roots resistant to soil-borne fungi. Pages 185-192 in: Biology and Control of Soil-borne Plant Pathogens. G. W. Bruehl ed. American Phytopathological Society, St. Paul, MN.

36. Paxton, J. D., and Groth, J. 1994. Constraints on pathogens attacking plants. Crit. Rev. Plant Sci. 13:77-95.

37. Pedras, M. S. C., Zheng, Q. A., and Sarma-Mamillapalle, V. K. 2007. The phytoalexins from Brassicaceae: Structure, biological activity, synthesis and biosynthesis. Nat. Prod. Commun. 2:319-330.

38. Philip, R., Darnowski, D. W., Maughan, P. J., and Vodkin, L. O. 2001. Processing and localization of bovine b-casein expressed in transgenic soybean seeds under control of a soybean lectin expression cassette, Plant Sci. 161:323-335.

39. Philip, R., Darnowski, D. W., Sundararaman, V., Cho, M.-J., and Vodkin, L. O. 1998. Localization of beta-glucuronidase in protein bodies of transgenic tobacco seed by fusion to an amino terminal sequence of the soybean lectin gene, Plant Sci. 137:191-204.

40. Saeed, H. A., Vodkin, L. O., and Stromvik, M. V. 2008. Promoters of the soybean seed lectin homologues Le2 and Le3 regulate gene expression in vegetative tissues in Arabidopsis. Plant Sci. 175:868-876.

41. Shimada, N., Sato, S., Akashi, T., Nakamura, Y., Tabata, S., Ayabe, S., and
Aoki, T. 2007. Genome-wide analyses of the structural gene families involved in the legume-specific 5-deoxyisoflavonoid biosynthesis of Lotus japonicas. DNA Res. 14:25-36.

42. Tuteja, L. H., Clough, S. J., Chan, W.-C., and Vodkin, L. O. 2004. Tissuespecific gene silencing mediated by a naturally occurring chalcone synthase gene cluster in Glycine max. Plant Cell 16:819-835.

43. Twizeyimana, M., Hill, C. B., Pawlowski, M., Paul, C., and Hartman, G. L. 2012. A cut-stem inoculation technique to evaluate soybean for resistance to Macrophomina phaseolina. Plant Dis. 96:1210-1215.

44. VanEtten, H., Temporini, E., and Wasmann, C. 2001. Phytoalexin (and phytoanticipin) tolerance as a virulence trait: Why is it not required by all pathogens? Physiol. Mol. Plant Pathol. 59:83-93.

45. VanEtten, H. D., Mansfield, J. W., Bailey, J. A., and Farmer, E. E. 1994. Two classes of plant antibiotics: Phytoalexins versus phytoanticipins. Plant Cell 6:1191-1192.

46. Veitch, N. C. 2007 Isoflavonoids of the Leguminosae. Nat. Prod. Rep. 24:417-464.

47. Verdaguer, B., Kochko, A., Beachy, R. N., and Faquet, C. 1996. Isolation and expression in transgenic tobacco and rice plants, of the cassava vein mosaic virus (CsVMV) promoter. Plant Mol. Biol. 31:1129-1139.

48. Ward, E. W. B. 1990. The interaction of soyabeans with Phytophthora megasperma f. sp. glycinea: Pathogenicity. Pages 311-327 in: Biological Control of Soil-borne Pathogens. B. Hornby, ed. CAB International, Wallingford, UK.

49. Zernova, O. V., Lygin, A. V., Widholm, J. M., and Lozovaya, V. V. 2009. Modification of isoflavones in soybean seeds via expression of multiple phenolic biosynthetic genes. Plant Physiol. Biochem. 47:769-777. 